\title{
Relationships between cock semen viability and the fertility of artificially inseminated South African indigenous chicken breeds
}

\author{
J.T. Molekwa and D.O. Umesiobi ${ }^{\#}$ \\ School of Agriculture and Environmental Sciences, Central University of Technology, Free State, Private Bag X20539, \\ Bloemfontein 9300, South Africa
}

\begin{abstract}
One hundred and sixty hens and 32 cocks of four different South African indigenous chicken breeds (Naked Neck (NN), Ovambo (OVB), Potchefstroom Koekoek (PK) and Venda (VD) were used in this study. Reproductive performance tests as determined by the number of ejaculations per five minutes of abdominal sexual massage (5ASM) were used to select 16 high performing (HP) and 16 low performing (LP) cocks from a population of 80 cocks. Cocks with $\geq 2$ ejaculates/60 min or $\leq 1$ ejaculate/60 min following ASM were considered as HP or LP cocks, respectively. Semen was collected from each cock following 5ASM, evaluated for semen viability and $0.05 \mathrm{~mL}$ diluted semen used to inseminate five hens per breed, in each experimental group. Significant differences in ejaculation rates and semen quality and quantity were recorded in the four breeds of cocks - with the HP cocks of the PK breed producing the highest ejaculation rate $(4.1 \pm 0.1 / 60 \mathrm{~min})$, ejaculate volume $(0.7 \pm 0.02 \mathrm{~mL})$, sperm motility $(92$ Class Test $2 \pm 0.7)$, percentage live sperm $(88.4 \pm 0.7 \%)$ and total sperm per ejaculate. Significant differences were also recorded in hen fertility and subsequent hatchability of set eggs. Semen from the HP cocks were superior to those from the LP cocks, as evidenced in most of the fertility and hatchability parameters, with PK layers producing eggs that gave the highest average egg weight $(58.04 \pm 0.9 \mathrm{~g})$, fertility $(74.3 \pm 0.2 \%)$, hatchability of set eggs $(84.03 \pm 0.7 \%)$, percentage of normal chicks $(98.1 \pm 0.7 \%)$ and chick weight $(37.9 \pm 0.3 \mathrm{~g})$. Results suggest that selection of high performing cocks following five minutes of sexual massage prior to semen collection enhances semen quality and quantity leading to significant improvement in the fertility of artificially inseminated hens.
\end{abstract}

Keywords: Cocks, semen viability, fertility, hatchability, indigenous chicken breeds

${ }^{\#}$ Corresponding author. E-mail: umesiobi@cut.ac.za

\section{Introduction}

The genetic diversity within South African indigenous chicken breeds is decreasing due to their replacement by high-producing exotic commercial hybrids. Indigenous breeds of chickens have been a product of their environment and have survived under the harsh conditions for many generations (Umesiobi, 2000; Fourie et al., 2004). The limited production of indigenous chicken breeds in large numbers, however, may be attributed to their slow growth rates, poor egg production (Sonaiya \& Odubote, 1997; Umesiobi, 2000; Okereke et al., 2008), high rearing mortalities and susceptibility to diseases (Adenokun \& Sonaiya, 2001). Several tests to evaluate semen quality have been described (Wishart et al., 2001; Umesiobi, 2004; Umesiobi et al., 2004; Umesiobi, 2006a; b), but they have rarely been applied in on-farm settings. The industry previously rather relied on the evaluation of semen using colour and volume parameters, which gave estimates of sperm quantity (Okereke et al., 2008).

Reproductive performance in the male comprises the production of semen containing normal sperm (quality) in adequate numbers (quantity), together with the desire (libido) and mating ability (servicing capacity). It is generally accepted that, although hens and cocks are genetically considered to be equal partners in the outcome of a mating, cock reproductive performance has a major impact on the reproductive efficiency of poultry operations (Bakst et al., 1994; Adenokun \& Sonaiya, 2001). By definition, semen from high performing males, with a relatively quick reaction time (Lunstra et al., 2002) and ejaculation rate (Bakst et al., 1994) can be used to inseminate a greater number of females per unit time, compared to semen from low performing males (Price, 1987; Langendijk, 2005).

If these hypotheses are true, then the quality and quantity of semen after sexual massage, may serve as indicators of the reproductive status of cocks. To test such a premise requires the use of sexually stimulated 
cocks, which would also permit the assessment of the effects of level of reproductive performance on semen viability and subsequent fertilising capacity of cocks. It is therefore imperative to understand and improve the semen viability of the indigenous cocks for subsequent improvement in the reproduction potential of indigenous hens. The present study was thus designed to investigate the ability of cocks to produce semen with adequate quality and quantity, with a resultant improvement in fertility of artificially inseminated hens.

\section{Materials and Methods}

One hundred and sixty hens and 32 cocks of four different South African indigenous chicken breeds, viz. the Naked Neck (NN), Ovambo (OVB), Potchefstroom Koekoek (PK) and Venda (VD)) were used to conduct this study at the Poultry Research Unit of the Agricultural Research Council (ARC), Glen, South Africa. The birds were reared to maturity at 20 weeks of age before the commencement of the trial, according to the guidelines provided by Adenokun et al. (2001) and Okereke et al. (2008). The trial was carried out during the period May 2005 to September 2006, for a period of 64 weeks.

Each cock was trained for semen collection using the five minutes abdominal sexual massage (5ASM) technique (Rodrigues \& Lok, 2000; Wishart et al., 2001). Reproductive performance tests as determined by number of ejaculations following 5ASM were used to select 16 high performing (HP) and 16 low performing (LP) cocks from a total population of 80 cocks. Cocks with $\geq 2$ ejaculates $/ 60 \mathrm{~min}$ or $\leq 1$ ejaculate $/ 60 \mathrm{~min}$ following ASM were considered as HP or LP cocks, respectively. Semen was collected from the 32 mature cocks once a week at 09:30 throughout the duration of the experiment, using the 5ASM as recommended by Umesiobi \& Iloeje (1999) and Wishart et al. (2001). The experimental hens were also assigned randomly to two groups consisting of 20 birds per group. Semen ( $0.05 \mathrm{~mL}$ diluted, VIRG-2) from each cock was used to inseminate five hens per breed, in each treatment. A total of 1600 hatching eggs (400 eggs per breed) were collected for incubation in three batches over the experimental period.

Eggs for hatching were collected twice a day (08:00 - 11:00 and 14:00 - 17:00) and marked according to the cock and hen two days after the first insemination. During hatching the eggs were turned automatically at 2-hourly intervals in a programmed incubator. On days 10 and 18 of incubation, the eggs were candled to identify and remove infertile or eggs with dead embryos (dead in germ). On day 21, hatchability parameters were recorded according to the respective breeds and treatments. The day-old chicks that hatched, were removed, vaccinated and transferred to the brooding pens and then reared in battery cages. The hatched chicks were recorded and observed for survivability.

Data on semen viability were analysed using the general linear model procedure of Statistical Analysis System, Version 9.1 (SAS, 2002). The correlation analysis procedure was used to extrapolate the relationships between the semen viability of cocks and fertility and hatchability traits between chicken breeds (McDonald, 2008).

\section{Results and Discussion}

Significant differences $(\mathrm{P}<0.05)$ were recorded regarding semen quality and quantity within and between breeds of cocks - with the HP cocks of the PK breed recording the highest ejaculation rate (4.09 $\pm 0.12 / 60 \mathrm{~min})$, ejaculate volume $(0.72 \pm 0.02 \mathrm{~mL})$, sperm motility $(92.0 \pm 0.7 \%)$, percentage live sperm cells $(88.35 \pm 0.72 \%)$ and total sperm per ejaculate (Table 1$)$. These findings were in agreement with the studies of Aganga et al. (2000) and Adenokun \& Sonaiya (2001) who reported that the superior reproductive potential exhibited by the various indigenous cock breeds showed that differences exist between the different breeds - similarly to that reported by Zahradden et al. (2002) and Okereke et al. (2008). Interestingly, Wishart et al. (2001) reported that the quantity of semen produced by male chickens to be not only dependent on the amount of sexual excitement, but also partly dependent upon a number of factors which include their physical temperament and sexual adjustment period such as stimulus changes (changes of teaser, semen collection or both).

The percentage range (31-95\%) of live sperm cells in the four breeds was much wider than the range (50.7 - 97.1\%) reported by Bayley \& Phororo (1992). This range difference may probably be attributed to different genotypes and management. Total sperm $\left(1.87 \pm 0.3 \times 10^{9} / \mathrm{mL}\right)$ obtained in this study from both HP and LP cocks were higher than the findings of Bakst et al. (1994). High fertility could therefore be achieved with the breeds studied, since Adenokun \& Sonaiya (2001) reported a very high positive correlation between total sperm and fertility. 
Table 1 Least square means ( \pm s.e.) for semen viability exhibited in the high-performing or low-performing South African Naked Neck (NKN), Ovambo (OVB), Potchefstroom Koekoek (PK) and Venda (VND) cock breeds

\begin{tabular}{|c|c|c|c|c|c|c|c|c|}
\hline & \multicolumn{8}{|c|}{ Cock breeds } \\
\hline & \multicolumn{2}{|c|}{ NKN } & \multicolumn{2}{|c|}{ OVB } & \multicolumn{2}{|c|}{ PK } & \multicolumn{2}{|c|}{ VND } \\
\hline & $\mathrm{HP}$ & LP & $\mathrm{HP}$ & LP & $\mathrm{HP}$ & LP & $\mathrm{HP}$ & LP \\
\hline Ejaculation rate & $2.6^{\mathrm{a}}$ & $0.6^{\mathrm{b}}$ & $3.1^{\mathrm{c}}$ & $0.8^{\mathrm{b}}$ & $4.1^{\mathrm{d}}$ & $1.0^{\mathrm{e}}$ & $1.4^{\mathrm{f}}$ & $0.3^{\mathrm{g}}$ \\
\hline (freq/60 min) & \pm 0.1 & \pm 0.1 & \pm 0.2 & \pm 0.1 & \pm 0.1 & \pm 0.1 & \pm 0.1 & \pm 0.1 \\
\hline Semen volume & $0.3^{\mathrm{a}}$ & $0.1^{\mathrm{b}}$ & $0.4^{\mathrm{c}}$ & $0.3^{\mathrm{d}}$ & $0.7^{\mathrm{e}}$ & $0.5^{\mathrm{f}}$ & $0.2^{\mathrm{g}}$ & $0.1^{\mathrm{h}}$ \\
\hline$(\mathrm{mL})$ & \pm 0.02 & \pm 0.03 & \pm 0.04 & \pm 0.03 & \pm 0.02 & \pm 0.01 & \pm 0.03 & \pm 0.1 \\
\hline \multirow[t]{2}{*}{ Sperm motility (\%) } & $65.2^{\mathrm{a}}$ & $50.3^{\mathrm{b}}$ & $77.2^{\mathrm{c}}$ & $54.5^{\mathrm{d}}$ & $92^{\mathrm{e}}$ & $60.2^{f}$ & $50.8^{\mathrm{af}}$ & $47.1^{\mathrm{g}}$ \\
\hline & \pm 1.3 & \pm 0.3 & \pm 0.6 & \pm 0.8 & \pm 0.7 & \pm 1.1 & \pm 1.1 & \pm 0.9 \\
\hline \multirow[t]{2}{*}{ Live sperm (\%) } & $54.6^{\mathrm{a}}$ & $38.9^{\mathrm{b}}$ & $72.9^{c}$ & $51^{\mathrm{d}}$ & $88.4^{\mathrm{e}}$ & $63.1^{\mathrm{f}}$ & $50.3^{\mathrm{g}}$ & $42.9^{\mathrm{h}}$ \\
\hline & \pm 0.6 & \pm 0.7 & \pm 0.9 & \pm 0.6 & \pm 0.7 & \pm 0.4 & \pm 0.6 & \pm 0.9 \\
\hline \multirow{2}{*}{$\begin{array}{c}\text { Total sperm } \\
\left(\mathrm{x} 10^{9} / \mathrm{mL}\right)\end{array}$} & $1.3^{\mathrm{a}}$ & $1^{\mathrm{b}}$ & $2.1^{\mathrm{c}}$ & $1.3^{\mathrm{d}}$ & $3.5^{\mathrm{e}}$ & $2.1^{\mathrm{c}}$ & $2.1^{\mathrm{c}}$ & $0.8^{\mathrm{f}}$ \\
\hline & \pm 0.01 & \pm 0.01 & \pm 0.1 & \pm 0.01 & \pm 0.04 & \pm 0.2 & \pm 0.01 & \pm 0.2 \\
\hline
\end{tabular}

\footnotetext{
${ }^{\mathrm{a}, \mathrm{h}}$ Means with different superscripts in a row are significantly different $(\mathrm{P}<0.01)$.

$\mathrm{HP}=$ High performing cocks.

$\mathrm{LP}=$ Low performing cocks.
}

Significant differences $(\mathrm{P}<0.05)$ were observed in most of the fertility and hatchability parameters recorded within and between the layer breeds. The HP cocks were significantly superior $(\mathrm{P}<0.05)$ to the LP cocks in the rate at which their semen sired offspring, as evidenced by the higher fertility and hatchability rates of the various breeds (Table 2). The HP cocks were superior to the LP cocks in promoting hen fertility and hatchability of eggs, with the PK layers producing eggs that gave the highest mean egg weight (58.0 $\pm 0.85 \mathrm{~g})$, fertility $(74.3 \pm 0.16 \%)$, hatchability of set eggs $(84.0 \pm 0.64 \%)$, percentage of normal chicks $(98.14 \pm 0.67 \%)$ and chick weight $(37.90 \pm 0.28 \mathrm{~g})$. Interestingly, NKN layers produced the highest percentage of live chicks $(95.7 \pm 0.44 \%)$. No significant differences were found within breeds regarding chicken weight.

Table 2 Least square means ( \pm s.e.) for fertility traits in South African Naked Neck (NKN), Ovambo (OVB), Potchefstroom Koekoek (PK) and Venda (VND) breeds following artificial insemination with semen from high-performing (HP) or low-performing (LP) cocks

\begin{tabular}{|c|c|c|c|c|c|c|c|c|}
\hline & \multicolumn{8}{|c|}{ Layer breeds } \\
\hline & \multicolumn{2}{|c|}{ NKN } & \multicolumn{2}{|c|}{ OVB } & \multicolumn{2}{|c|}{ PK } & \multicolumn{2}{|c|}{ VND } \\
\hline & $\mathrm{HP}$ & LP & $\mathrm{HP}$ & LP & $\mathrm{HP}$ & LP & $\mathrm{HP}$ & LP \\
\hline \multirow[t]{2}{*}{ Mean egg weight (g) } & $40.8^{\mathrm{a}}$ & $37.1^{b}$ & $56.8^{\mathrm{c}}$ & $40.4^{\mathrm{a}}$ & $58^{\mathrm{d}}$ & $55.5^{\mathrm{e}}$ & $54.3^{\mathrm{f}}$ & $51.2^{\mathrm{g}}$ \\
\hline & \pm 0.1 & \pm 0.5 & \pm 0.4 & \pm 1.0 & \pm 0.9 & \pm 0.6 & \pm 0.9 & \pm 0.5 \\
\hline \multirow[t]{2}{*}{ Fertility (\%) } & $60.8^{\mathrm{a}}$ & $50.6^{\mathrm{b}}$ & $70.6^{\mathrm{c}}$ & $52.1^{\mathrm{d}}$ & $74.3^{\mathrm{e}}$ & $68.2^{\mathrm{f}}$ & $60.8^{\mathrm{a}}$ & $53.8^{\mathrm{g}}$ \\
\hline & \pm 1.3 & \pm 0.3 & \pm 0.1 & \pm 0.3 & \pm 0.2 & \pm 0.5 & \pm 0.5 & \pm 0.3 \\
\hline \multirow{2}{*}{$\begin{array}{l}\text { Hatchability on set } \\
\text { eggs }(\%)\end{array}$} & $83.3^{\mathrm{a}}$ & $71.1^{\mathrm{b}}$ & $77.5^{\mathrm{c}}$ & $70.2^{\mathrm{d}}$ & $84^{\mathrm{e}}$ & $78.6^{\mathrm{f}}$ & $66.5^{\mathrm{g}}$ & $60.9^{\mathrm{h}}$ \\
\hline & \pm 0.8 & \pm 0.6 & \pm 0.6 & \pm 0.7 & \pm 0.6 & \pm 0.5 & \pm 0.6 & \pm 1.1 \\
\hline \multirow[t]{2}{*}{ Live chicks $(\%)$} & $95.7^{\mathrm{a}}$ & $80.2^{b}$ & $79.1^{\mathrm{c}}$ & $75.4^{\mathrm{d}}$ & $71^{\mathrm{e}}$ & $66^{\mathrm{f}}$ & $75.9^{\mathrm{g}}$ & $70.2^{\mathrm{h}}$ \\
\hline & \pm 0.4 & \pm 0.5 & \pm 1.1 & \pm 0.4 & \pm 0.5 & \pm 0.7 & \pm 0.2 & \pm 0.2 \\
\hline \multirow[t]{2}{*}{ Normal chicks (\%) } & $87.9^{\mathrm{a}}$ & $75.8^{b}$ & $87.8^{c}$ & $71.5^{\mathrm{d}}$ & $98.1^{\mathrm{e}}$ & $80.1^{\mathrm{f}}$ & $76.9^{\mathrm{g}}$ & $61.4^{\mathrm{h}}$ \\
\hline & \pm 0.6 & \pm 0.9 & \pm 0.5 & \pm 0.3 & \pm 0.7 & \pm 0.3 & \pm 0.5 & \pm 0.9 \\
\hline \multirow[t]{2}{*}{ Chick weight (g) } & $23.5^{\mathrm{a}}$ & $23.5^{\mathrm{a}}$ & $32.8^{\mathrm{b}}$ & $32.8^{\mathrm{b}}$ & $37.9^{c}$ & $37.9^{c}$ & $26.9^{d}$ & $26.9^{\mathrm{d}}$ \\
\hline & \pm 0.1 & \pm 0.1 & \pm 0.5 & \pm 0.5 & \pm 0.3 & \pm 0.3 & \pm 0.4 & \pm 0.4 \\
\hline
\end{tabular}

${ }^{a, h}$ Means with different superscripts in a row are significantly different $(\mathrm{P}<0.05)$. 
As no known change or procedure was introduced during semen collection and insemination, these outstanding and consistent improvements in hatchability and fertility of AI layers recorded in this study tend to support earlier evidence (Bakst et al., 1994; Umesiobi \& Iloeje, 1999; Adenokun et al., 2001; Umesiobi, 2004; Umesiobi et al., 2004; 2006a; b) that the ability of the sperm cells to survive during capacitation in a female reproductive tract may be dependent on a male's ability in donating optimum quality semen following five minutes of sexual massage. However, the highest fertility recorded for the heavy breed PK, compared to other breeds in the current study contradicts the reports by Bayley \& Phororo (1992), who observed high fertility in lighter breeds. This difference could be because the PK has a better inherent adaptation potential than any of the local breeds studied. Differences in fertility between batches (in different periods) are in agreement with reports of Wishart et al. (2001). Differences in hatchability of total eggs set between breeds signify that in this study hatchability of total eggs recorded was a function of fertility. Furthermore, this finding of hatchability of total eggs set, agrees with that of Adenokun \& Sonaiya (2001), who found significant differences in hatchability of fertile eggs between breeds. It also agrees with Bakst et al. (1994), who found the hatchability for indigenous breeds regarding set eggs to be higher than in the exotic breeds.

\section{Conclusions}

Results suggest that the selection of high performing cocks following five minutes of sexual massage prior to semen collection enhances semen quality and quantity, and leads to a significant improvement in the fertility of artificially inseminated hens. This is an important consideration as studies on semen viability tests in which the semen viability of potential cocks was determined avails the breeder the opportunity to assess the fertility proficiency of cocks before their use in AI programmes. The presence of cocks with low reproductive performance in a pen increases the total number of cocks required and also limits the genetic contribution from individual cocks.

Considering the overall fertility and hatchability traits, it is concluded that breed has a significant effect on fertility and hatchability of fertile eggs in indigenous layer breeds. Fertility and hatchability of set eggs is significantly higher in the Potchefstroom Koekoek (PK), compared to Naked Necks, Ovambo and Venda under South African conditions. The Potchefstroom Koekoek layers appear to be superior to the other breeds in terms of the fertility and hatchability parameters. The results obtained in this study showed that the use of semen from high performing (HP) cocks following five minutes of sexual massage is a practical method for optimising sperm viability and the subsequent fertility in hens.

\section{Acknowledgements}

This study was supported by grant-in-aid for innovative research from the Central University of Technology, Free State Province, South Africa. Research resources, equipment and space provision by the Agricultural Research Council are gratefully acknowledged.

\section{References}

Adenokun, S.D. \& Sonaiya, E.B., 2001. Comparison of the performance of Nigerian chickens from three agro-ecological zones. Livest. Res. Rural Dev. 13, 2-5.

Aganga, A.A., Tsoenyane, S.O. \&. Molefhe, L., 2003. Influence of feed type on egg production of laying chicken. Int. J. Anim. Sci. 2 (4), 256-258.

Bakst, M.R., Wishart, G.J. \& Brillard, J.P., 1994. Oviducal sperm selection, transport and storage in poultry. Poult. Sci. Rev. 5, 117-143.

Bayley, B. \& Phororo, H., 1992. An analysis of egg marketing in Lesotho: implications of liberization. Institute of South African Studies. National University of Lesotho. Roma, Lesotho.

Fourie, H.J., Swatson, H.K., Grobbelaar, J.A.N., Molalakgotla, M.N. \& Joosten, F.A., 2004. Fowls for Africa. In: Proc. XXII World Poultry Congress, Istanbul, June 8-13, 2004.

Langendijk, P., 2005. Is there a future for the boar? The role of boar stimuli in reproductive processes around estrus in the pig. $\mathrm{PhD}$ thesis, Department of Animal Science, Wageningen Institute of Animal Sciences, Wageningen University, Wageningen, The Netherlands. pp. 1-197.

Lunstra, D.D., Wise, T.H. \& Ford, J.J., 2002. Sertoli cells in the boar testis: Changes during development and compensatory hypertrophy after hemicastration at different ages. Biol. Reprod. 68, 140-150. 
McDonald, J.H., 2008. Handbook of Biological Statistics. Sparky House Publishing, Baltimore, Maryland, USA. pp. $1-28$.

Okereke, C.O., Ukachukwu, S.N. \& Umesiobi, D.O., 2008. Assessment of egg production indices of layers following dietary inclusion of composite cassava (Manihot esculanta) meal. J. Appl. Anim. Res. 33, 69-72.

Price, E.O., 1987. Male sexual behaviour. Vet. Clinics N. Amer. Food Anim. Pract. 3, 405-422.

Rodrigues, D.L. \& Lok, R., 2000. Improving egg production in two indigenous communities through the adaptation of management practices and local knowledge: The results of participative research. The New York Academy of Sciences, New York.

SAS, 2002. Statistical Analysis System user's guide. Version 9.1. Statistical Analytical Institute Inc., Cary, North Carolina, USA.

Sonaiya, E.B. \& Odubote, I.K., 1997. Socio-economics, characteristics and performance of Nigerian poultry ecotypes and their crosses with Dahlem Red. In: Proc.International Workshop held on December 9-13, 1997 at M'Bur, Senegal. Ed. Sonaiya, E.B., Publishers: INFPD. M’Bur, Senegal pp. 19-26.

Umesiobi, D.O., 2000. Animal Production. I. Basic Principles and Practices. Bean Blaise Publication, Owerri, Nigeria.

Umesiobi, D.O., 2004. Functional integrity of boar spermatozoa and sow fertility using raphia (Raphia hookeri) palmwine plus 'Nche' (Saccoglotis gabonensis) Urban extender. J. Appl. Anim. Res. 26, 13-16.

Umesiobi, D.O., 2006a. Effect of oral administration of Clomiphene citrate on sperm viability and fertility of boar semen. J. Appl. Anim. Res. 30, 167-170.

Umesiobi, D.O., 2006b. The effect of hemi-orchidectomy on reproductive traits of boars. S. Afr. J. Anim. Sci. 36, 181-188.

Umesiobi, D.O. \& Iloeje, M.U., 1999. Effect of sexual teasing and diurnal period of semen collection on reaction time and semen characteristics of Large White boars. J. Sustain. Agric. Environ. 1, 231-235.

Umesiobi, D.O., Kalu, U., Ogundu, Iloeje, M.U., Anyanwu, U. \& McDowell, L.R., 2004. Fertility studies on two methods of libido maintenance in West African Dwarf rams. J. Anim. Vet. Adv. 3, 81-84.

Wishart, G.J., Staines, H.J. \& Hazary, R.C., 2001. Evaluation of fertility: biological basis and practical application. Poult. Sci. 57, 309-314. 